\title{
Microbial Mannosidation of Bioactive Chlorogentisyl Alcohol by the Marine-Derived Fungus Chrysosporium synchronum
}

\author{
Keumja Yun, ${ }^{a}$ Chinni Mahesh KondemPudi,${ }^{a}$ Hong Dae Chol, ${ }^{b}$ Jung Sook Kang, ${ }^{c}$ and \\ Byeng Wha Son $*, a$ \\ ${ }^{a}$ Department of Chemistry, Pukyong National University; Busan 608-737, Korea: ${ }^{b}$ Department of Chemistry, Dongeui \\ University; Busan 614-714, Korea: and ${ }^{c}$ College of Dentistry, Pusan National University; Yangsan, Gyeongnam 626-770, \\ Korea. Received November 25, 2010; accepted January 6, 2011; published online January 7, 2011
}

The biological transformation of the biologically active chlorogentisyl alcohol (1), isolated from the marinederived fungus Aspergillus sp., was studied. Preparative-scale fermentation of chlorogentisyl alcohol with marine-derived fungus Chrysosporium synchronum resulted in the isolation of a new glycosidic metabolite, 1- $O-(\alpha-$ D-mannopyranosyl)chlorogentisyl alcohol (2). The stereostructure of the new metabolite obtained was assigned on the basis of detailed spectroscopic data analyses, chemical reaction, and chemical synthesis. Compounds 1 and 2 exhibited significant radical-scavenging activity against 1,1-diphenyl-2-picrylhydrazyl radical (DPPH) with $\mathrm{IC}_{50}$ values of 1.0 and $4.7 \mu \mathrm{M}$, respectively. The compounds 1 and 2 were more active than the positive control, $\mathrm{L}-$ ascorbic acid $\left(\mathrm{IC}_{50}, \mathbf{2 0 . 0} \mu_{\mathrm{M}}\right)$.

Key words marine-derived fungus; Chrysosporium synchronum; microbial mannosidation; 1-O-( $\alpha$-D-mannopyranosyl)chlorogentisyl alcohol

The aim of our program is to explore the biological transformation of bioactive metabolites produced by microorganisms isolated from marine habitats. As part of this program, we identified the marine-derived ascomycete strains and actinomycete strains that regioselectively oxidize bioactive natural products to new and more active compounds: from terreusinone to the unsymmetrical alcohol derivative, terreusinol, by Streptomyces sp., ${ }^{1)}$ from 6- $n$-pentyl- $\alpha$-pyrone to two oxidized metabolites, 6- $n$-(4-oxopentyl)- $\alpha$-pyrone and 6$n$-[(S)-1-hydroxypentyl]- $\alpha$-pyrone, by Streptomyces sp., ${ }^{2)}$ from cyclonerodiol to three metabolites, $10(Z)-, 10(E)$-cyclonerotriol, and cyclonerodiol mannopyranoside, by the genus of Streptomyces and Penicillium, ${ }^{3)}$ from geraniol to its 7-oxidized metabolite, 1,7-dihydroxy-3,7-dimethyl-(E)-oct2-ene, by Hypocrea sp., ${ }^{4)}$ and from (-)-mellein to $(3 R, 4 S)-4-$ hydroxymellein by Stappia sp. ${ }^{5}$ In our continuing study of applications of microbial transformations, ${ }^{6}$ we screened 50 cultures for their ability to biotransform chlorogentisyl alcohol (1). Chlorogentisyl alcohol was isolated from the marine algicolous fungus Aspergillus sp. ${ }^{7}$ and was found to induce apoptosis in $\mathrm{HeLa}$ cells. ${ }^{8}$ ) The marine-derived fungus Chrysosporium synchronum was selected as the biotransforming target strain.

Preliminary small-scale fermentations $(100 \mathrm{ml})$ of $C$. synchronum, with the addition of monosaccharides (e.g., glucose, galactose, mannose, rhamnose, or ribose) directly to the culture medium, respectively, did not provide promising result except for mannose. TLC analyses of the broth extracts confirmed that mannose only stimulated mannoside production relative to a control culture.

Biotransformation of chlorogentisyl alcohol was carried out using the marine-derived fungus $C$. synchronum according to a two-stage fermentation protocol. ${ }^{9)}$ The fermentations of $1(20 \mathrm{mg})$ with $C$. synchronum were harvested after two weeks, and the filtered broths were extracted with EtOAc to afford crude extracts. The extract was purified by repeated silica gel flash chromatography ( $n$-hexane in ethyl acetate) and HPLC (octadesyl silica (ODS), $\mathrm{MeOH}-\mathrm{H}_{2} \mathrm{O}$ ) to yield a new glycoside, $1-O-(\alpha$-D-mannopyranosyl)chlorogentisyl alcohol (2) (3.2 mg). The metabolite 2, $[\alpha]_{\mathrm{D}}+3.70(c=0.3$, $\mathrm{MeOH}$ ), was isolated as a colorless oil. A molecular formula of $\mathrm{C}_{13} \mathrm{H}_{17} \mathrm{ClO}_{8}$ was established by high resolution electrospray ionization mass spectrometry (HR-ESI-MS) and ${ }^{13} \mathrm{C}$ NMR methods. The IR spectrum of $\mathbf{2}$ suggested the presence of hydroxyl $\left(3400 \mathrm{~cm}^{-1}\right)$ and glycosidic $\left(1018 \mathrm{~cm}^{-1}\right)$ groups. The ${ }^{1} \mathrm{H}$ - and ${ }^{13} \mathrm{C}-\mathrm{NMR}$ data of $\mathbf{2}$ closely resembled those of $\mathbf{1}$ except for the appearance of additional proton signals corresponding to the five $s p^{3}$ oxymethines and one oxymethylene. An extensive analysis of the distortionless enhancement by polarization transfer (DEPT) and 2D-NMR spectra, correlation spectroscopy (COSY), heteronuclear multiple quantum correlation (HMQC), and heteronuclear multiple bond coherence (HMBC), and nuclear Overhauser effect spectroscopy (NOESY) experiments, suggested that $\mathbf{2}$ was a glycoside comprising 1 as an aglycone and one sugar unit. The hexopyranose unit was presumed to be mannose due to the anti diaxial orientations of $\mathrm{H}-3^{\prime} / \mathrm{H}-4^{\prime}\left(J_{\mathrm{H}^{\prime}-\mathrm{H} 4^{\prime}}=9.1 \mathrm{~Hz}\right)$ and $\mathrm{H}-4^{\prime} / \mathrm{H}-$ $5^{\prime}\left(J_{\mathrm{H}^{\prime}-\mathrm{H} 5^{\prime}}=9.5 \mathrm{~Hz}\right)$ and the syn equatorial and axial orientation of $\mathrm{H}-2^{\prime} / \mathrm{H}-3^{\prime} \quad\left(J_{\mathrm{H}^{\prime}-\mathrm{H} 3^{\prime}}=3.2 \mathrm{~Hz}\right)$ in the ${ }^{1} \mathrm{H}-\mathrm{NMR}$ $\left(\mathrm{CD}_{3} \mathrm{OD}\right)$. Acid hydrolysis of $\mathbf{2}$ furnished $\mathbf{1}$ and methyl mannose, ${ }^{10)}$ and the latter was identified on the basis of GC and GC-MS analyses of the trimethylsilyl derivative. Comparison of the ${ }^{13} \mathrm{C}-\mathrm{NMR}$ data of $\mathbf{1}$ and $\mathbf{2}$, and the key HMBC correlation from $\mathrm{H}-1^{\prime}$ to $\mathrm{C}-1$ were critical in establishing the position of mannose as attached at the 1-OH of $\mathbf{1}$. The stereochemistry of the anomeric position of the sugar moiety was assigned as the $\alpha$-configuration on the basis of the anomeric carbon signal at $\delta 100.9\left(\mathrm{~d}, \mathrm{C}-1^{\prime}\right)$ having a ${ }^{1} J_{\mathrm{C}-\mathrm{H}}$ value of $175 \mathrm{~Hz} .{ }^{11)}$ This value was deduced from DEPT nondecoupling measurements. The absolute configuration of the mannose unit was determined to be $\mathrm{D}$ from measurement of the optical rotation. Obtained from acid hydrolysis of $\mathbf{2}$ with $9 \%$ aq. $\mathrm{HCl}$, the specific rotation of mannose, $[\alpha]_{\mathrm{D}}^{20}+28.8$ $\left(c=0.03, \mathrm{H}_{2} \mathrm{O}\right)$, indicated the presence of D-mannose in 2 $\left[\right.$ ref: $\left.[\alpha]_{\mathrm{D}}^{20}+29.3\right]{ }^{12)}$ These results led us to conclude that the structure of compound 2 was 1-O-( $\alpha$-D-annopyranosyl)- 
chlorogentisyl alcohol (Fig. 1). To clarify the structure of $\mathbf{2}$, we synthesized 2 from 1 and 1-O-(2,3,4,6-tetra- $O$-acetyl- $\alpha$ D-mannopyranosyl)trichloroacetimide. D-(+)-Mannose was acetylated by acetic anhydride in pyridine, followed by selective deacetylation of 1 -acetyl group by piperidine to give 2,3,4,6-tetra- $O$-acetyl-D-mannopyranoside. ${ }^{13)}$ Treatment with trichloroacetonitrile of the $\mathrm{C}$-1-unprotected mannopyranose, 2,3,4,6-tetra- $O$-acetyl-D-mannopyranoside, afforded 1-O(2,3,4,6-tetra- $O$-acetyl-D-mannopyranosyl)trichloroacetimide. ${ }^{14,15)}$ Glycosidation of $\mathbf{1}$ with the above imidate in the presence of boron trifluoro-etherate ${ }^{16)}$ provided 1-O- $(2,3,4,6$ tetra- $O$-acetyl- $\alpha$-D-mannopyranosyl)chlorogentisyl alcohols (2a) in $25 \%$ yield as a major product as well as two minor products, $4-O$-(2,3,4,6-tetra- $O$-acetyl- $\alpha$-D-mannopyranosyl)chlorogentisyl alcohol (2b) and 7-O-(2,3,4,6-tetra-O-acetyl$\alpha$-D-mannopyranosyl)chlorogentisyl alcohol (2c), in trace amounts (Fig. 2). The $\alpha$-configuration at $\mathrm{C}-1^{\prime}$ of 2 a was substantiated by the small value of the coupling constant $[\delta 5.49$ $\left.\left(1 \mathrm{H}, \mathrm{br} \mathrm{s}, \mathrm{H}-1^{\prime}\right)\right]$ of the anomeric proton. Finally, the product 2a was subjected to alkaline hydrolysis $(\mathrm{NaOMe})$ to afford $\mathbf{2}$. The spectroscopic data for the synthetic compound were identical to those of compound 2 in $[\alpha]_{\mathrm{D}}$, ESI-MS, and ${ }^{1} \mathrm{H}-$ NMR. Although many examples of microbial glucosidation have been reported, ${ }^{17-19)}$ microbial mannosidation is very rare. ${ }^{3)}$ Thus, to the best of our knowledge, compound $\mathbf{2}$ is the second example of microbial mannosidation by the marine isolate of the microorganism. Compounds $\mathbf{1}$ and $\mathbf{2}$ exhibited significant radical scavenging activity against 1,1-diphenyl2-picrylhydrazyl radical (DPPH), with $\mathrm{IC}_{50}$ values of 1.0 and $4.7 \mu \mathrm{M}$, respectively. They were more active than the positive control, L-ascorbic acid $\left(\mathrm{IC}_{50}, 20.0 \mu \mathrm{M}\right)$. We plan to intensively examine compounds $\mathbf{1}$ and $\mathbf{2}$ for inhibitory activity

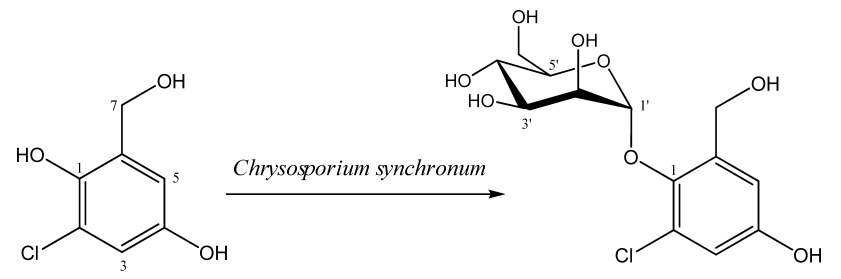

1

2

Fig. 1. Microbial Mannosidation of Chlorogentisyl Alcohol (1) and the Structure of Metabolite, 1-O-( $\alpha$-D-Mannopyranosyl)chlorogentisyl Alcohol (2)

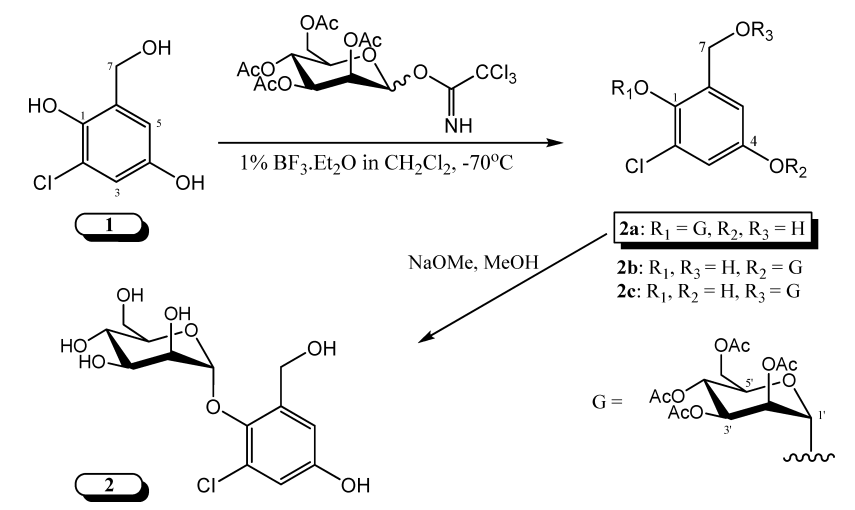

Fig. 2. Synthesis of 1-O-( $\alpha$-D-Mannopyranosyl)chlorogentisyl Alcohol (2) from Chlorogensyl Alcohol (1) against epidermal growth factor receptor (EGFR), ${ }^{20,21)}$ and the results will be reported in due course.

\section{Experimental}

General Optical rotation was determined on a Perkin Elmer model 341 polarimeter. UV/visible spectra were measured on a Hitachi U-2001 UV/Vis spectrometer. IR spectra were recorded on a Bruker Fourier transform (FT)IR model IFS-88 spectrometer. ${ }^{1} \mathrm{H}-(400 \mathrm{MHz})$ and ${ }^{13} \mathrm{C}-\mathrm{NMR}(100 \mathrm{MHz})$ spectra were obtained on a JEOL JNM-ECP 400 NMR spectrometer, using tetramethylsilane (TMS) or solvent peaks [DMSO- $d_{6}:{ }^{1} \mathrm{H}(\delta 2.50)$ and ${ }^{13} \mathrm{C}(\delta$ 39.5)] as reference standard. LC-MS and MS spectra were obtained on API 2000 (Applied Bio System, U.S.A.) and IT-TOF (Shimadzu, Japan) spectrometer, respectively. HPLC was performed on a Young Lin ACME HPLC system using a reversed-phase analytical column (Gemini C18, $4.6 \times 250 \mathrm{~mm}, 5 \mu \mathrm{m}$ ) with UV detection. Incubations of microorganisms and biotransformations were performed on an Incubator Shaker JS-FS-2500 (Johnsam Co., Inchon, Korea).

Fungal Isolation The fungal strain was isolated from the surface of edible brown alga Sargassum ringgoldium (Korean name: KeunIp Mojaban) collected at Yokji Island of GyeongNam, Korea in 2009, and identified to be C. synchronum (EMBL/AM943023.1) on the basis of morphology and 18S ribosomal RNA (rRNA) analysis (SolGent Co., Ltd., Daejeon, Korea), identity of $98 \%$. A voucher specimen is deposited at Pukyong National University with the code BAac049.

Biotransformation of 1 A two-stage fermentation protocol ${ }^{9)}$ was used for preparative scale formation of the metabolite of $\mathbf{1}$. The modified medium contained soytone $(0.1 \%)$, soluble starch $(1.0 \%)$, mannose $(0.1 \%)$, and seawater $(100 \%)$, and it was autoclaved at $121^{\circ} \mathrm{C}$ for $15 \mathrm{~min}$. Preparative incubation was conducted in 11 of sterile medium held in 31 culture flask that was incubated on a rotary shaker $(130 \mathrm{rpm})$ at $29^{\circ} \mathrm{C}$ for 1 week. A $10 \%$ inoculum derived from one week old stage I culture was used to initiate stage II culture, which was incubated for $24 \mathrm{~h}$ more under the same condition before receiving $20 \mathrm{mg}$ of $\mathbf{1}$ in $0.75 \mathrm{ml}$ of $N, N$-dimethyl formamide (DMF), and incubation was continued at $29^{\circ} \mathrm{C}$ for two weeks in the same manner to that described above. Substrate control consisted of sterile medium and substrate incubated under the same conditions but without microorganism. Also, culture control was composed of fermentation blanks in which the microorganism was grown under identical condition but without the addition of substrate. After two weeks of incubation, each control was harvested and analyzed by TLC. The culture was filtered through cheesecloth, and the filtrate was extracted with EtOAc. The organic layer was dried over anhydrous $\mathrm{Na}_{2} \mathrm{SO}_{4}$, filtered through sintered glass, and vacuum-concentrated to yield a crude extract $(95 \mathrm{mg})$.

Isolation of the Metabolite (2) The crude extract (95 mg) was subjected to silica gel flash column chromatography. Elution was performed with $n$-hexane-EtOAc (stepwise, $0-100 \%$ EtOAc) to yield three fractions. Fractions 2 and 3 were separated by medium-pressure liquid chromatography (MPLC) (ODS) using a $\mathrm{H}_{2} \mathrm{O}-\mathrm{MeOH}$ gradient elution to afford crude $\mathbf{1}$ and 2, respectively. These were further purified by HPLC (Gemini C18, $4.6 \times 250 \mathrm{~mm}, 5 \mu \mathrm{m})$ utilizing a $30 \mathrm{~min}$ gradient program of 50 to $100 \%$ $\mathrm{MeOH}$ in $\mathrm{H}_{2} \mathrm{O}$ to furnish the substrate, $\mathbf{1}(8.5 \mathrm{mg})$, and the metabolite (2) $(3.2 \mathrm{mg})$, respectively.

1-O-( $\alpha$-D-Mannopyranosyl)chlorogentisyl alcohol (2): A colorless oil; $[\alpha]_{\mathrm{D}}^{20}+3.70(c=0.3, \mathrm{MeOH}) ; \mathrm{UV}(\mathrm{MeOH}) \lambda_{\max }(\log \varepsilon) 275(3.3), 207(0.6)$ $\mathrm{nm}$; IR (KBr) $v_{\max } 3400,2924,1627,1241,1018 \mathrm{~cm}^{+1}$; ${ }^{1} \mathrm{H}-\mathrm{NMR}\left(\mathrm{CD}_{3} \mathrm{OD}\right.$, $400 \mathrm{MHz}) \delta: 7.03(2 \mathrm{H}, \mathrm{s}, \mathrm{H}-3,5), 4.64\left(2 \mathrm{H}, \mathrm{s}, \mathrm{H}_{2}-7\right), 5.37(1 \mathrm{H}, \mathrm{d}, J=1.5 \mathrm{~Hz}$, $\left.\mathrm{H}-1^{\prime}\right), 3.98\left(1 \mathrm{H}, \mathrm{dd}, J=3.2,1.5 \mathrm{~Hz}, \mathrm{H}-2^{\prime}\right), 3.87(1 \mathrm{H}, \mathrm{dd}, J=9.1,3.2 \mathrm{~Hz}, \mathrm{H}-$ $\left.3^{\prime}\right)$, $3.74-3.76\left(3 \mathrm{H}, \mathrm{m}, \mathrm{H}-4^{\prime}, 6^{\prime}\right), 3.60\left(1 \mathrm{H}, \mathrm{dt}, J=9.5,4.0 \mathrm{~Hz}, \mathrm{H}-5^{\prime}\right) ;{ }^{13} \mathrm{C}-$ NMR (CD $\left.{ }_{3} \mathrm{OD}, 100 \mathrm{MHz}\right) \delta: 150.9$ (s, C-1), 132.0 (s, C-2), 117.6 (d, C-3), 146.7 (s, C-4), 116.3 (d, C-5), 121.6 (s, C-6), 60.9 (t, C-7), 100.9 (d, C-1'), 71.9 (d, C-2'), $72.2\left(\mathrm{~d}, \mathrm{C}-3^{\prime}\right), 68.1\left(\mathrm{~d}, \mathrm{C}-4^{\prime}\right), 75.3\left(\mathrm{~d}, \mathrm{C}-5^{\prime}\right), 62.2$ (t, C-6'); low resolution (LR)-ESI-MS: $m / z$ 335 $\left[\mathrm{M}\left({ }^{35} \mathrm{Cl}\right)-\mathrm{H}\right]$ and $337\left[\mathrm{M}^{*}\right.$ $\left.\left({ }^{37} \mathrm{Cl}\right)-\mathrm{H}\right](m / z \quad 335: 337=c a .3: 1)$; HR-ESI-MS: $m / z \quad 335.0538[\mathrm{M}-\mathrm{H}]$ (Calcd for $\left.\mathrm{C}_{13} \mathrm{H}_{16} \mathrm{O}_{8} \mathrm{Cl}, 335.0539\right)(-0.30 \mathrm{ppm})$.

Acid Hydrolysis of 2, and Sugar Analysis A solution of $2(0.5 \mathrm{mg})$ in $9 \%$ dry methanolic $\mathrm{HCl}(1.0 \mathrm{ml})$ was stirred at $80^{\circ} \mathrm{C}$ for $1 \mathrm{~h}\left(\mathrm{~N}_{2}\right.$ atmosphere). The reaction mixture was neutralized with $\mathrm{Ag}_{2} \mathrm{CO}_{3}$ and filtrated. The residue, obtained by removal of the solvent, was dissolved in pyridine $(0.5 \mathrm{ml})$ and treated with bis(trimethylsilyl)trifluoroacetamide (BSTFA) $(0.5 \mathrm{ml})$ at $\mathrm{rt}$ for $30 \mathrm{~min}$. Solvent was removed by a nitrogen stream and the residue dissolved in $n$-hexane was used for GC-MS analysis [(DB-1MS column, $60 \mathrm{~m} \times 0.32 \mathrm{~mm}$ ); $\mathrm{N}_{2}$ as a carrier gas at $0.7 \mathrm{ml} / \mathrm{min}$; the program rate: $80-260^{\circ} \mathrm{C}$ at $5^{\circ} \mathrm{C} / \mathrm{min}$ ] showing peak at $t_{\mathrm{R}} 16.60 \mathrm{~min}$, which corresponded to those of TMS/Me derivative of mannose $\left(\mathrm{m} / z 540[\mathrm{M}]^{+}\right)$. 
Determination of the Stereochemistry of the Mannopyranose A solution of $2(1.0 \mathrm{mg})$ in $9 \%$ aq. $\mathrm{HCl}(1.0 \mathrm{ml})$ was stirred at $80^{\circ} \mathrm{C}$ for $1 \mathrm{~h}$. The reaction mixture was treated as described above, and the residue thus obtained was partitioned into $\mathrm{H}_{2} \mathrm{O}$ and $\mathrm{CH}_{2} \mathrm{Cl}_{2}$ to give the organic phase and the aqueous phase. The aqueous portion was applied to a Diaion HP-20 column (Mitsubishi Kasei, Japan, $20 \mathrm{ml}$ of resin, $10 \times 250 \mathrm{~mm}$ ). The column was eluted with distilled water $(100 \mathrm{ml})$ and $\mathrm{MeOH}(100 \mathrm{ml})$, successively. The elute with $\mathrm{MeOH}$ was concentrated to afford mannose $(0.3 \mathrm{mg})$. The rotation recorded for mannose isolated in this study was $[\alpha]_{\mathrm{D}}+28.8(c=0.03$, $\left.\mathrm{H}_{2} \mathrm{O}\right)$, which showed D-mannose in 2 [ref: $\left.[\alpha]_{\mathrm{D}}^{20}+29.3\right] .{ }^{12)}$

Synthesis of 2 Molecular sieves 4A $(60 \mathrm{mg})$ and 1-O-(2,3,4,6-tetra- $O$ acetyl-D-mannopyranosyl)trichloroacetimide $\quad(38 \mathrm{mg}, \quad 0.08 \mathrm{mmol})$ were added to a solution of $1(15 \mathrm{mg}, 0.08 \mathrm{mmol})$ in $\operatorname{dry~} \mathrm{CH}_{2} \mathrm{Cl}_{2}(7 \mathrm{ml})$ at $\mathrm{rt}$, then the mixture was treated with boron trifluoro-etherate $(1 \%$ solution in dry $\left.\mathrm{CH}_{2} \mathrm{Cl}_{2}, 0.5 \mathrm{ml}\right)$ at $-70^{\circ} \mathrm{C}$ for $2 \mathrm{~h}$. The reaction mixture was poured into ice water, and the whole was extracted with $\mathrm{CH}_{2} \mathrm{Cl}_{2}$. The organic phase was washed with aq. saturated $\mathrm{NaHCO}_{3}$ and brine, then dried over $\mathrm{MgSO}_{4}$. Removal of the solvent under reduced pressure gave a product that was purified by column chromatography $\left(\mathrm{SiO}_{2}, n\right.$-hexane-EtOAc $\left.=5: 1\right)$ to afford not only $1-O$-(2,3,4,6-tetra- $O$-acetyl- $\alpha$-D-mannopyranosyl)chlorogentisyl alcohol (2a) $(9.0 \mathrm{mg}, 0.02 \mathrm{mmol}, 25 \%)$ as the major product, but also the minor products, $\quad 4-O$ - $(2,3,4,6$-tetra- $O$-acetyl- $\alpha$-D-mannopyranosyl)chlorogentisyl alcohol (2b) and 7-O-(2,3,4,6-tetra- $O$-acetyl- $\alpha$-D-mannopyranosyl)chlorogentisyl alcohol (2c) in trace amounts. A solution of $\mathbf{2 a}(9 \mathrm{mg}, 0.02 \mathrm{mmol})$ in $\mathrm{MeOH}(2 \mathrm{ml})$ was treated with $28 \% \mathrm{NaOMe}(1 \mathrm{drop})$ at $\mathrm{rt}$ for $4 \mathrm{~h}$. The reaction mixture was neutralized with Dowex $\left[50 \mathrm{~W} \times 8\left(\mathrm{H}^{+}\right.\right.$form $\left.)\right]$, and the resin was removed by filtration. Removal of the solvent from the filtrate under reduced pressure gave a product $(10 \mathrm{mg})$ that was purified by reversed-phase ODS-A gel (YMC Co., Japan) flash column chromatography using $\mathrm{MeOH}$, followed by HPLC (ODS, $\mathrm{MeOH}-\mathrm{H}_{2} \mathrm{O}=5: 1$ ) to furnish 2 (4.8 $\mathrm{mg}$, $0.01 \mathrm{mmol}, 50 \%$ ) (Fig. 2). The spectroscopic data $\left([\alpha]_{\mathrm{D}}\right.$, ESI-MS, and ${ }^{1} \mathrm{H}-$ NMR) for the synthetic compound were virtually identical to those of the natural product (2).

Radical Scavenging Activity against DPPH ${ }^{7)}$ Samples (1, 2, and positive control, L-ascorbic acid) to be tested were dissolved in $\mathrm{MeOH}$ and the solution $(160 \mu \mathrm{l})$ was dispensed into wells of a 96 -well microtiter tray. Forty microliters of the DPPH solution in $\mathrm{MeOH}\left(1.5 \times 10^{-4} \mathrm{M}\right)$ was added to each well. The mixture was shaken and left to stand for $30 \mathrm{~min}$, and the absorbance of the resulting solution was measured at $520 \mathrm{~nm}$ with microplate reader (Packard Co., U.S.A., Spectra Count ${ }^{\mathrm{TM}}$ ). The scavenging activity on DPPH radical was expressed as $\mathrm{IC}_{50}$, which is the concentration of the tested compound required to give a $50 \%$ decrease of the absorbance from that of the blank solution [consisting of $\mathrm{MeOH}(160 \mu \mathrm{l})$ and $\mathrm{DPPH}$ solution $(40 \mu 1)]$

Acknowledgment This research was supported by the National Research Foundation of Korea Grant funded by the Korean Government (MOEHRD, Basic Research Promotion Fund) (KRF-2008-314-F00048). Mass spectral data were kindly provided by the Korea Basic Science Insti- tute. The second Brain Korea 21 graduate fellowship grant to students and a post-doctor (CMK) is gratefully acknowledged (09B2519).

\section{References}

1) Li X., Lee S. M., Choi H. D., Kang J. S., Son B. W., Chem. Pharm. Bull., 51, 1458-1459 (2003).

2) Li X., Kim S.-K., Jung J. H., Kang J. S., Choi H. D., Son B. W., Bull. Korean Chem. Soc., 26, 1889-1890 (2005).

3) Li X., Kim Y. H., Jung J. H., Kang J. S., Kim D.-K., Choi H. D., Son B. W., Enz. Microbial. Technol., 40, 1188-1192 (2007).

4) Leutou A. S., Yang G., Nenkep V. N., Siwe X. N., Feng Z., Khong T. T., Choi H. D., Kang J. S., Son B. W., J. Microbiol. Biotechnol., 19, $1150-1152$ (2009)

5) Feng Z., Nenkep V. N., Yun K., Zhang D., Choi H. D., Kang J. S., Son B. W., J. Microbiol. Biotechnol., 20, 985-987 (2010).

6) Nenkep V. N., Yun K., Li Y., Choi H. D., Kang J. S., Son B. W., J. Antibiot., 63, 199-201 (2010).

7) Li Y., Li X., Son B. W., Nat. Prod. Sci., 11, 136-138 (2005)

8) Zhang Y., Ahn E.-Y., Jiang Y., Kim D.-K., Kang S.-G., Wu C., Kang S.-W., Park J.-S., Son B. W., Jung J. H., Int. J. Oncology, 31, 13171323 (2007).

9) Smith R. V., Rosazza J. P., J. Pharm. Sci., 64, 1737-1759 (1975).

10) Stothers J. B., "Carbon-13 NMR Spectroscopy," Academic Press, London, 1972, p. 461.

11) Pretsch E., Buhlmann P., Affolter C., "Structure Determination of Organic Compounds, Tables of Spectral Data,' Springer, Berlin, 2000, p. 153.

12) "The Merck Index, an Encyclopedia of Chemicals, Drugs, and Biologicals," Twelfth Edition; ed. by Budavari S., O’Neil M. J., Smith A., Heckelman P. E., Kinneary J. F., Merck \& Co., New Jersey, 1996, p. 979.

13) van Boeckel C. A. A., Beetz T., Vos J. N., de Jong A. J. M., van Aelst S. F., van den Bosch R. H., Mertens J. M. R., van der Vlugt F. A., J. Carbohydr. Chem., 4, 293-321 (1985).

14) Zhou Y., Lin F., Chen J., Yu B., Carbohydr. Res., 341, 1619-1629 (2006).

15) Schmidt R. R., Michel J., Angew. Chem. Int. Ed. Engl., 19, 731-732 (1980).

16) Shibuya H., Kawashima K., Narita N., Ikeda M., Kitagawa I., Chem. Pharm. Bull., 40, 1154-1165 (1992).

17) Orabi K. Y., Clark A. M., Hufford C. D., J. Nat. Prod., 63, 396-398 (2000).

18) Shim H., Hong W., Ahn Y., Bull. Korean Chem. Soc., 24, 1680-1682 (2003).

19) Yim S.-H., Kim H. J., Lee I.-S., Arch. Pharm. Res., 26, 805-808 (2003).

20) Ranson M., Br. J. Cancer, 90, 2250-2255 (2004).

21) Jorissen R. N., Walker F., Pouliot N., Garrett T. P., Ward C. W., Burgess A. W., Exp. Cell Res., 284, 31-53 (2003). 